\title{
ANALISIS PERBAIKAN MENU UNPOPULAR DI RESTORAN DAPUR SUNDA DI KOTA JAKARTA
}

\author{
Dani Adiatma, Wendi Andriatna, dan Agus Sudono \\ Program Studi Manajemen Industri Katering \\ Fakultas Pendidikan Ilmu Pengetahuan Sosial \\ Universitas Pendidikan Indonesia Bandung 40154 \\ e-mail : daniadiatma@yahoo.com
}

\begin{abstract}
The purpose of this research is knowing analysis repair menu unpopular in stimultan in a Dapur Sunda restaurant

Methods in use anava.A population that in use in research this ampunt is a menu, and long months surveyed in a Dapur Sunda restauran. Type samples used namely sampling saturated about 195 respondents. Analysis fo data research is analysis menu engineering, analysis quality products using quisioner, analysis anava. Technical data in do study literature, method survey, descriptive analytic method through a questionaire, interview and the study of literature.

The results of this research show that the unpopular enough influence each month to the development of special revenue and also the restaurant dapur sunda. From the result of this research was then in need of good engineering menu settings Keywords : the unpopular mеnu, a menu engineering and Dapur Sunda restaurant
\end{abstract}

\begin{abstract}
Abstrak
Tujuan dari penelitian ini adalah mengetahui analisis perbaikan menu unpopular secara stimultan di restoran dapur sunda

Metode yang di gunakan Anava. Populasi yang di gunakan dalam penelitian ini adalah jumlah menu, dan lama bulan yang diteliti di restoran Dapur Sunda. Jenis sampel yang digunakan yaitu sampling jenuh sebanyak 195 responden. Analisis data dalam penelitian ini yaitu analisis menu engineering, analisis kualitas produk menggunakan kuisioner, analisis anava. Teknik pengumpulan data yang di lakukan studi literatur, metode survey, metode deskriptif analitik melalui kuesioner, wawancara dan studi literatur.

Hasil Penelitian ini menunjukan bahwa menu unpopular cukup berpengaruh tiap bulanya terhadap pengembangan menu dan juga pendapatan restoran Dapur Sunda.Dari hasil penelitian ini maka di perlukan pengaturan menu engineering yang baik

Kata kunci: menu unpopular, menu engineering dan restoran Dapur Sunda
\end{abstract}

\section{PENDAHULUAN}

Pariwisata di Indonesia mengalami perkembangan yang sangat pesat dan penghasilan devisa negara yang nilainya pun tidak sedikit. Hal ini terbukti pada tahun 2011 devisa dari sektor pariwisata menunjukankan angka 8 Miliar dollar USA 
atau sekitar 75 Triliun dan angka ini menempatkan sektor pariwisata diurutan kelima penyumbang devisa negara (Pos Kota 2011, jumat 30 Desember - 18:25, sumber http://Pos Kota.co.id).

Wisata sangat identik dengan kuliner, biasanya para wisatawan selain ingin menikmati fasilitas wisata yang ada para wisatawan juga ingin menikmati kuliner yang ada di suatu restoran yang ada di daerah tersebut.

Menurut Suarthana (2006:23) restoran adalah "tempat usaha yang komersial yang ruang lingkup kegiatannya menyediakan pekayanan makanan dan minuman untuk umum di tempat usahanya".

Menurut Sihite (2000:16) restoran adalah "suatu tempat dimana seseorang yang datang menjadi tamu yang akan mendapatkan pelayanan untuk menikmati makanan, baik pagi, siang, ataupun malam sesuai dengan jam bukanya dan oleh tamu yang menikmati hidangan itu harus membayar sesuai dengan harga yang ditentukan sesuai daftar yang disediakan di restoran itu".

Jenis jenis restoran berdasarkan pelayanan yaituGrill Room,Dining Room, Coffee Shop, Cafetaria, Continental Restaurant, Supper Club, Night Club, Speciality Restaurant.

Pada masa sebelum abad ke-18, daftar makanan yang ditulis sederhana, biasanya dipajang pada pintu restoran. Daftar makanan yang singkat itu disebut escriteau. Beberapa saat kemudian, daftar makanan tersebut, daftar makanan tersebut berpindah tempat dari luar ke dalam restoran dan dipajangkan diatas meja makan. Ada kalanya masing-masing tamu pengunjung restoran disediakan satu lembar daftar makanan untuk memudahkan memilih makanan yang sesuai dengan selera mereka masing-masing daftar makanan ini kemudian dikenal dengan nama menu.

Restoran sebagai tempat makan kemudian makin populer, dan variasi makanan yang dicantumkan pada daftar tersebut makin lama makin banyak. Akhirnya menu berfungsi sebagai daftar makanan yang dapat dipesan dan dinikmati saat itu juga. Pada tahun 1765 tuan Boulagere membuka sebuah restoran di Paris, dan memajang poster besar di depan restoran untuk mengumumkan makan yang disediakan pada hari tersebut.

Jenis jenis menu ada 3 yaitu menu A'la carte, Table d'hote Menu dan special party menu. Menu dapat pula dikelompokkan berdasarkan pada jenis hidangan ( meal ), seperti :

1) Breakfast menu ( menu hidangan makan pagi ),

2) Luncheon тепи ( menu hidangan makan siang ),

3) Tea time тепи ( menu hidangan ringan pengiring minum teh sore ),

4) Dinner menu ( menu hidangan makan malam ),

5) Supper menu ( menu hidangan makan larut malam ),

6) Banquet menu ( menu hidangan perjamuan ),

7) Buffet menu ( menu hidangan prasmanan )

Mungkin inilah kelahiran Menu a'la carte yang pertama, yang kemudian digunakan di berbagai restoran. Makin lama makin banyak perbaikan dan peningkatan dilakukan misalnya pada tata cara penulisan, seni penampilan, tata warna dan lain sebagainya. Banyak seniman-seniman ternama diminta merancang penampilan menu sehingga nilai menu semakin lama semakin meningkat. Banyak 
orang menggandrungi sebuah hobi baru, yaitu mengumpulkan menu dari berbagai restoran bahkan membeli menu tersebut dengan harga yang cukup mahal. Itu semua semata-mata hanya dijadikan koleksi pribadi saja.

Pada usaha jasa-boga saat ini, menu memegang peranan penting, karena merupakan jembatan yang menghubungkan hotel/restoran dengan pelanggan/tamu.

Penyusun menu memerlukan pengalaman dan pengetahuan yang cukup baik dibidang pengolahan maupun pada penyajian makanan. Perencanaan dan penyusunan menu menyangkut beberapa orang yang secara langsung saling berhubungan yaitu:

a) Chef de Cuisine (Kepala Dapur)

b) Restaurant Manager (Kepala Restoran)

c) Manager or Owner (Manager atau Pemilik Perusahaan)

Seringkali pimpinan ataupun pemilik perusahaan kurang menyadari pengaruh menu makanan pada kepuasan langganan. Menu dianggap kurang diharapkan, sehingga penampilannya kurang baik dan berpengaruh buruk pada reputasi perusahaan secara umum.

Dalam hubungan ini, kata menu diartikan as a list of the dishes which are available to a customer atau sebagai daftar makanan yang tersedia untuk pelanggan atau tamu.

Menu juga berarti a bill of fare atau daftar makanan. Daftar/menu dapat ditulis pada sehelai kertas, sebidang karton ataupun diatas selembar kain. Perencanaan dan penyusunan menu adalah suatu tugas penting bagi usaha perhotelan dan restoran, maupun usaha jasa boga lainnya. Banyak faktor-faktor yang harus dipertimbangkan baik pada waktu perencanaan, maupun pada waktu penyusunan menu.

Dapur Sunda di dirikan pada tahun 1986 oleh H. Ansoroeddin dan seluruh keluarga, dan Dapur Sunda Cipete reputasi pertama sejak restoran keluarga berdiri. Setelah beberapa tahun bisnis berkembang pesat dan meningkatkan penjualan telah berhasil untuk membuka delapan cabang yang tersebar di seluruh Jakarta. Oleh karena itu,Dapur Sunda dapat dikatakan turut menunjang perkembangan ekonomi khusunya untuk kota Jakarta dan untuk Indonesia pada umumnya.

Saat ini Dapur Sunda memiliki lebih dari 300 tenaga kerja, baru-baru ini cabang Dapur Sunda di Utara Jakarta ada dua cabang, dan satu cabang baru di buka di Mall Of Indonesia ( MOI ) dan yang lainya adalah di Gading Food City, Di daerah Selatan Jakarta ada enam cabang :

1. Jl. Cipete Raya No. 13

2. Hanggar Teras MBAU Pancoran, Jl. Jend Gatot Subroto

3. Setiabudi Building One

4. Bellagio Butik Mall, di Kawasan Mega Kuningan

5. Pondok Indah Mall III B, Jl. Metro kencana

6. Pacific Place One, Kawasan SCBD Sudirman

Dengan bertambahnya jumlah cabang restoran dapur sunda membuktikan bahwa restoran ini sedang mengalami perkembangan yang cukup pesat. Semakin berkembangnya sebuah usaha maka perusahaan akan berusaha untuk meningkatkan menu unpopular untuk membuat menu unpopular tersebut menjadi menu yang popular. 
Untuk meningkatkan menu unpopular diperlukan menu engineering yang baik dalam mengelola menu yang menyangkut total penjualan, total pendapatan, contribution margin, kepopuleran suatu menu agar menu unpopular tersebut meningkat menjadi menu yang popular.

Dalam hal ini restoran dapur sunda belum memiliki penanganan menu engineering yang baik. Ini terlihat dari cukup banyaknya jenis menu yang ditawarkan tetapi dari total penjualanya didominasi oleh beberapa menu tertentu yang sudah popular seperti pada tabel dibawah ini :

Tabel 1.1

Data Penjualan Restoran Dapur Sunda

Periode Januari - Juni 2012

\begin{tabular}{|c|c|c|c|c|c|c|}
\hline \multirow{2}{*}{ Menu } & \multicolumn{7}{|c|}{ Total Penjualan Bulan Ke } \\
\cline { 2 - 7 } & 1 & 2 & 3 & 4 & 5 & 6 \\
\hline sop & & & & & & \\
\hline sop ikan gurame & 2.052 & 2.736 & 2.460 & 2.634 & 2.424 & 2.610 \\
\hline sop ikan mas & 25 & 30 & 23 & 22 & 26 & 22 \\
\hline sop selat sunda & 348 & 330 & 366 & 354 & 306 & 342 \\
\hline soto bandung & 2.214 & 1.788 & 1.632 & 1.608 & 2.436 & 1.866 \\
\hline mie kocok & 202 & 214 & 220 & 211 & 218 & 230 \\
\hline sayur asem & 2.748 & 2.370 & 2.898 & 2.772 & 2.928 & 2.934 \\
\hline soto ayam & 390 & 276 & 312 & 198 & 426 & 264 \\
\hline sop ayam & 193 & 202 & 212 & 190 & 179 & 220 \\
\hline sop Buntut & 1.182 & 1.212 & 858 & 1.194 & 1.128 & 1.290 \\
\hline sop iga sapi & 708 & 642 & 420 & 408 & 594 & 468 \\
\hline Sapi & & & & & & \\
\hline Empal Goreng & 3.774 & 3.498 & 3.840 & 3.462 & 3.768 & 4.422 \\
\hline Paru Goreng & 1.854 & 1.632 & 1.494 & 1.362 & 1.794 & 2.088 \\
\hline Babat Goreng & 1.008 & 798 & 594 & 780 & 852 & 756 \\
\hline Usus Goreng & 882 & 684 & 702 & 420 & 864 & 696 \\
\hline Ikan & & & & & & \\
\hline Gurame Goreng & 4.506 & 5.064 & 4.914 & 3.684 & 5.226 & 4.902 \\
\hline Gurame Bakar & 2.196 & 1.938 & 2.478 & 1.698 & 2.460 & 2.172 \\
\hline $\begin{array}{c}\text { Gurame Goreng } \\
\text { Cobek }\end{array}$ & 313 & 304 & 289 & 320 & 345 & 327 \\
\hline $\begin{array}{c}\text { Gurame Bakar } \\
\text { Cobek }\end{array}$ & 1.026 & 1.026 & 1.056 & 930 & 2.880 & 1.098 \\
\hline $\begin{array}{c}\text { Gurame Garang } \\
\text { Asam }\end{array}$ & 198 & 179 & 184 & 196 & 202 & 193 \\
\hline Gurame Goreng & 180 & 195 & 207 & 218 & 211 & 204 \\
\hline
\end{tabular}




\begin{tabular}{|c|c|c|c|c|c|c|} 
Acar & & & & & & \\
\hline Gurame Tumis & 732 & 726 & 714 & 498 & 684 & 690 \\
\hline Ikan Mas Goreng & 2 & 3 & 1 & 2 & 2 & 3 \\
\hline Ikan Mas Bakar & 0 & 1 & 3 & 1 & 2 & 3 \\
\hline Pepes Ikan Mas & 293 & 285 & 296 & 305 & 300 & 301 \\
\hline $\begin{array}{c}\text { Ikan Mas Goreng } \\
\text { Acar }\end{array}$ & 26 & 20 & 17 & 22 & 28 & 23 \\
\hline Ikan Mas Tumis & & & & & & \\
\hline $\begin{array}{c}\text { Ikan Mas Garang } \\
\text { Asam }\end{array}$ & 12 & 8 & 10 & 9 & 14 & 9 \\
\hline Jambal Goreng & 606 & 540 & 696 & 516 & 594 & 498 \\
\hline Ayam & & & & & & \\
\hline Ayam Goreng & 3.324 & 2.970 & 2.952 & 2.142 & 2.634 & 3.096 \\
\hline Ayam Bakar & 4.218 & 3.612 & 3.522 & 2.520 & 3.282 & 3.114 \\
\hline $\begin{array}{c}\text { Ayam Geprek } \\
\text { Goreng }\end{array}$ & 780 & 798 & 678 & 954 & 714 & 618 \\
\hline $\begin{array}{c}\text { Ayam Geprek } \\
\text { Bakar }\end{array}$ & 580 & 602 & 589 & 595 & 601 & 596 \\
\hline Pepes Ayam & 140 & 128 & 118 & 127 & 129 & 125 \\
\hline Sate Ayam & 4.290 & 3.888 & 3.966 & 2.988 & 3.894 & 4.242 \\
\hline Ati Ampela Goreng & 185 & 198 & 190 & 201 & 197 & 193 \\
\hline Ati Ampela Bakar & 33 & 26 & 22 & 28 & 37 & 29 \\
\hline Hidangan Laut & & & & & & \\
\hline Udang Goreng & 11 & 6 & 8 & 7 & 10 & 8 \\
\hline Udang Bakar & 293 & 285 & 296 & 305 & 300 & 301 \\
\hline $\begin{array}{c}\text { Udang Goreng } \\
\text { Tepung }\end{array}$ & 372 & 335 & 359 & 383 & 379 & 375 \\
\hline $\begin{array}{c}\text { Udang Goreng } \\
\text { Mentega }\end{array}$ & 744 & 1.002 & 894 & 666 & 594 & 882 \\
\hline Cumi Goreng & 4 & 6 & 4 & 7 & 9 & 6 \\
\hline $\begin{array}{c}\text { Cumi Bakar } \\
\text { Cumi Goreng }\end{array}$ & 205 & 211 & 223 & 206 & 211 & 216 \\
\hline $\begin{array}{c}\text { Tepung } \\
\text { Meni Goreng }\end{array}$ & 127 & 121 & 132 & 139 & 144 & 138 \\
\hline Nasi & 1.344 & 666 & 1.044 & 1.314 & 1.374 & 1.152 \\
\hline Nasi Goreng & 5.534 & 5.520 & 4.848 & 5.244 & 5.472 & 5.958 \\
\hline Sayuran & Karedok & 5.202 & 2.976 & 3.294 \\
\hline
\end{tabular}




\begin{tabular}{|c|c|c|c|c|c|c|}
\hline Lotek & 468 & 696 & 468 & 558 & 312 & 570 \\
\hline Urab Sayuran & 564 & 498 & 642 & 630 & 438 & 576 \\
\hline Tumis Toge Babat & 119 & 108 & 126 & 139 & 120 & 122 \\
\hline Tumis Toge Jambal & 2.850 & 2.940 & 3.174 & 2.892 & 3.360 & 3.696 \\
\hline Tumis Toge Tahu & 810 & 1.074 & 894 & 996 & 894 & 894 \\
\hline Tumis Kangkung & 2.694 & 2.448 & 2.640 & 2.256 & 2.550 & 2.970 \\
\hline Tumis Lember & 78 & 85 & 88 & 79 & 82 & 82 \\
\hline Lalab Sambal & 924 & 1.026 & 846 & 1.038 & 1.368 & 1.122 \\
\hline Cobek Genjer & 618 & 402 & 408 & 648 & 420 & 390 \\
\hline Pepes Tahu & 378 & 396 & 462 & 462 & 444 & 522 \\
\hline Tahu/tempe Goreng & 5.772 & 3.432 & 3.312 & 3.528 & 4.074 & 4.608 \\
\hline $\begin{array}{l}\text { Tahu Goreng } \\
\text { Tepung }\end{array}$ & 444 & 546 & 534 & 546 & 522 & 642 \\
\hline $\begin{array}{c}\text { Tempe Goreng } \\
\text { Tepung }\end{array}$ & 480 & 498 & 468 & 480 & 438 & 432 \\
\hline Semur Jengkol & 348 & 336 & 300 & 342 & 732 & 828 \\
\hline Jengkol Goreng & 104 & 99 & 108 & 115 & 110 & 109 \\
\hline Pete Goreng & 324 & 366 & 366 & 372 & 360 & 270 \\
\hline Pete Bakar & 378 & 342 & 336 & 384 & 348 & 402 \\
\hline Pepes Jamur & 948 & 618 & 402 & 408 & 546 & 846 \\
\hline Pete Telor & 378 & 306 & 366 & 312 & 282 & 282 \\
\hline Tahu Telor & 2.370 & 2.586 & 2.262 & 2.190 & 2.622 & 2.790 \\
\hline Pencok Kacang & 354 & 294 & 234 & 276 & -258 & 258 \\
\hline Pencok Leunca & 19 & 16 & 22 & 27 & 33 & 24 \\
\hline Ulukuteuk Leunca & 306 & 385 & 390 & 522 & 306 & 426 \\
\hline Emping Goreng & 252 & 498 & 504 & 252 & 492 & 492 \\
\hline \multicolumn{7}{|l|}{ Sambal } \\
\hline Sambal Tempe & & & & & & 2.088 \\
\hline $\begin{array}{c}\text { Sambal Tempe } \\
\text { Terasi }\end{array}$ & 3.660 & 3.948 & 3.552 & 3.462 & 3.906 & 5.040 \\
\hline Sambal Oncom & 210 & 234 & 254 & 227 & 210 & 336 \\
\hline Sambal Mentah & 2.874 & 2.808 & 2.352 & 2.616 & 2.502 & 3.264 \\
\hline Sambal Tomat & 534 & 480 & 714 & 378 & 768 & 522 \\
\hline Sambal Gandaria & 384 & 384 & 396 & 384 & 414 & 354 \\
\hline Sambal manga & 1.740 & 1.752 & 1.608 & 1.578 & 1.860 & 1.560 \\
\hline \multicolumn{7}{|l|}{ Hidangan Penutup } \\
\hline Biji Salak & 450 & 516 & 462 & 456 & 420 & 234 \\
\hline
\end{tabular}




\begin{tabular}{|c|c|c|c|c|c|c|} 
Rujak Serut & 432 & 432 & 462 & 564 & 594 & 636 \\
\hline Pisang Goreng & 438 & 468 & 636 & 390 & 408 & 558 \\
\hline Colenak & 516 & 726 & 528 & 732 & 852 & 966 \\
\hline TOTAL & 85.794 & 81.548 & 79.619 & 74.281 & 86.377 & 91.885 \\
\hline
\end{tabular}

Sumber : pra penelitian di restoran dapur sunda 2012

Berdasarkan data penjualan seperti tabel 1.1 di atas kemudian penulis mengelompokan kedalam beberapa kelas menu engineering yaitu stars, plowhorse, puzzle dan dog. Seteah dihitung muncul beberapa menu yang masuk kedalam kategori menu unpopular yaitu menu dog seperti pada tabel dibawah ini :

Tabel 1.2

Tabel Pengklafikasian Menu Dog

\begin{tabular}{|c|c|c|c|}
\hline nama menu & $\begin{array}{c}\text { MM \% } \\
\text { category }\end{array}$ & $\begin{array}{c}\text { CM } \\
\text { Category }\end{array}$ & $\begin{array}{c}\text { klasifikasi } \\
\text { menu }\end{array}$ \\
\hline Usus Goreng & Low & Low & Dog \\
\hline Jambal Goreng & Low & Low & Dog \\
\hline Ati Ampela Goreng & Low & Low & dog \\
\hline Ati Ampela Bakar & Low & Low & dog \\
\hline Lotek & Low & Low & dog \\
\hline Urab Sayuran & Low & Low & dog \\
\hline Tumis Toge Babat & Low & Low & dog \\
\hline Lalab Sambal & Low & Low & dog \\
\hline Cobek Genjer & Low & Low & dog \\
\hline Pepes Tahu & Low & Low & dog \\
\hline Tahu Goreng Tepung & Low & Low & dog \\
\hline Tempe Goreng Tepung & Low & Low & dog \\
\hline Semur Jengkol & Low & Low & dog \\
\hline Jengkol Goreng & low & Low & dog \\
\hline Pete Goreng & low & Low & dog \\
\hline Pete Bakar & low & Low & dog \\
\hline Pepes Jamur & low & Low & dog \\
\hline Pete Telor & low & Low & dog \\
\hline Pencok Kacang & low & Low & dog \\
\hline Pencok Leunca & low & Low & dog \\
\hline Ulukuteuk Leunca & low & Low & dog \\
\hline Emping Goreng & low & Low & dog \\
\hline Sambal Tempe & low & Low & dog \\
\hline Sambal Oncom & low & Low & dog \\
\hline Sambal Tomat & low & Low & dog \\
\hline Sambal Gandaria & low & Low & dog \\
\hline Biji Salak & low & Low & dog \\
\hline Rujak Serut & low & Low & dog \\
\hline Pisang Goreng & low & Low & dog \\
\hline
\end{tabular}




\begin{tabular}{|l|l|l|l|} 
Colenak & low & Low & dog \\
\hline
\end{tabular}

Sumber : pra penelitian di restoran dapur sunda 2012

Dari tabel 1.2 kita bisa melihat ada 30 jenis menu atau sekitar $37 \%$ yang termasuk kategori dog dari 81 menu yang ditawarkan. Cukup banyaknya menu yang masuk kedalam golongan menu unpopular dan berdasarkan fenomena penjualan menu engginering di atas penulis tertarik untuk membahas dan meneliti menu engginering dengan judul "ANALISIS PERBAIKAN MENU UNPOPULAR DI RESTORAN DAPUR SUNDA DI KOTA JAKARTA”

\section{METODE PENELITIAN}

Metode penelitian yang digunakan yaitu metode studi literatur, survey dan deskriptif analitik. Penelitian ini terdiri dari tiga variabel yaitu rasa, aroma dan penampilan.

Metode yang digunakan yaitu statistik deskriptif analitik dimana studi literatur, dan kuesioner sebagai alat pengumpul data.

Tahapaan dalam penelitian ini yaitu:

- Menu Engineering

- Karateristik organoleptik

- Kuisioner tentang rasa, aroma dan penampilan

- Survey pengujian

- Kesimpulan

- Rekomendasi perbaikan menu

Populasi pada penelitian ini berjumlah 3000 konsumen per bulan di restoran Dapur Sunda di kota Jakarta

\section{OPERASIONAL VARIABEL}

\section{A. Rasa}

Kualitas empat rasa dasar dipengaruhi oleh konsentrasinya. Rasa manis pada gula akan bertambah apabila konsentrasi gula semakin tinggi tetapi sampai konsentrasi tertentu rasa enak yang ditimbulkannya akan menurun. Begitu pula pada ketiga rasa yang lain.

Umumnya bahan pangan tidak hanya terdiri dari salah satu rasa, tetapi merupakan gabungan berbagai macam rasa secara terpadu sehingga menimbulkan cita rasa yang utuh. Kecuali itu rasa suatu bahan pangan merupakan hasil kerjasama indera - indera yang lain. Indera penglihatan, pembauan, pandangan dan perabaan ikut berperan dalam pengamatan rasa bahan pangan.

Sel penerima rasa terletak pada papila fungifore (berbentuk seperti jarum) dan berada di bagian ujung dan tengah lidah bagian atas dan papila sirkumvalat di bagian belakang lidah. Dalam seluruh papila terdapat kuncup rasa dimana bila terangsang akan meneruskan ransangan tersebut ke otak.

Dalam hal kepekaan rasa, maka rasa manis dapat mudah dirasakan pada ujung lidah, rasa asin pada ujung dan pinggir lidah, rasa asam pada pinggir lidah dan rasa pahit pada bagian belakang lidah. 
Selain adanya pengaruh dari konsentrasi, hal lain yang berpengaruh pada keempat rasa pokok adalah :

1) Suhu

2) Medium raasa yang dipakai

3) Adaptasi

4) Interaksi beberapa macam rasa

\section{B. Aroma}

bau-bauan atau aroma dapat didefinisikan sebagai sesuatu yang dapat diamati dengan indera pembau. Untuk dapat menghasilkan bau, zat -zat bau harus dapat menguap, sedikit larut dalam air dan sedikit dapat larut dalam lemak.

Di dalam industri pangan pengujian terhadap bau di anggap penting karena dengan cepat dapat memberikan hasil penilaian terhadap produk tentang diterima atau tidaknya produk tersebut.Kecuali itu bau dapat dipakai juga sebagai suatu indikator terjadinya kerusakan pada produk.

Misalnya akibat cara pengemasan atau cara penyimpanan yang kurang baik. Namun demikian dengan bau-bauan ini timbul dunia usaha baru berupa produksi masking agent misalnya permen yang dapat menutup bau bawang, rokok, dan lain lain. Dalam pengujian inderawi bau lebih komplek daripada rasa. Bau atau aroma dan suatu produk dapat diamati baik dengan cara membau maupun dengan merasakan

Zat yang menghasilkan bau sering lebih kuat diamati dengan merasakan daripada dengan membau. Ada dua cara dalam mengamati bau :

1) lewat indera pembau, dimana ransangan akan diterima oleh regio alfactoria yaitu suatu bagian pada bagian atas rongga hidung.

2) Lewat mulut terutama bagi mereka yang sukar mengamat lewat hidung

\section{Penampilan}

sifat penglihatan atau penampilan merupakan sifat pertama yang diamati oleh konsumen sedangkan sifat - sifat yang lain akan dinilai kemudian.

Pada bahan pangan yang berada dalam suatu kemasan, maka kemasan dan label merupakan suatu hal yang penting sebagai pendukung kenampakan produk. Termasuk dalam sifat penglihatan ini adalah :

1) Warna dan kilap

2) Viskositas

3) Ukuran dan bentuk

4) Sifat kelainan bahan

\section{HASIL PEMBAHASAN}

Saat ini restoran sunda di kota Jakarta cukup mengalami peningkatan yang pesat ini dapat dilihat dari semakin banyaknya restoran restoran baru yang menyajikan makanan khas sunda. Sehingga membuat restoran dapur sunda harus melakukan perbaikan menu agar dapat tetap bersaing dengan restoran yang baru

Konsumen pun dewasa ini cukup banyak yang memilih restoran yang menyajikan menu sunda karena rasa dan aroma yang menggugah selera sehingga cukup potensial untuk terus dikembangkan ditengah banyaknya restoran yang menyajikan masakan dari luar negeri 
Menu masakan khas sunda cukup beragam sehingga membuat para konsumen meminati makanan khas sunda karena cukup bervariasi menu yang ditawarkannya

Berdasarkan penelitian konsumen Restaurant Dapur Sunda didominasi oleh laki-laki, dengan rata -rata usia 21 - 40 tahun, latar pendidikan S-1, status pekerjaan mahasiswa, PNS, pegawai swasta, dan rata-rata penghasilan mereka 2,5 - 5 juta rupiah.

Dari hasil perhitungan tabel menu engginering di atas terdapat 12 menu berkategori stars, 25 menu berkategori puzzzle, 13 menu berkategori plowhorse, dan 30 menu berkategori dog. Dengan average contribution marginya (ACM) senilai Rp. 13.633,55 dengan index parsial menu mixnya (MM\%) yaitu 0,86\%.

Dalam kategori sop, menu yang terpopuler ialah sop ikan gurame, soto bandung dan sop buntut. Dalam kategori ikan, menu yang terpopuler ialah gurame goreng, gurame bakar, gurame bakar cobek. Dalam kategori ayam menu yang terpopuler adalah ayam goreng, ayam bakar, ayam geprek goreng. Dalam kategori hidangan laut menu yeng terpopuler adalah udang goreng mentega, cumi goreng tepung. Dalam kategori nasi menu yang terpopuler ialah nasi goreng.

Dalam kategori sapi menu yang unpopular adalah usus goreng. Dalam kategori ikan menu yang unpopular adalah jambal goreng. Dalam kategori ayam, menu yang unpopular adalah ati ampela goreng, ati ampela bakar. Dalam kategori sayuran, menu yang unpopular adalah lotek, urab sayuran, tumis toge babat, lalab sambal, cobek genjer, pepes tahu, tahu goreng tepung, tempe goreng tepung, semur jengkol, jengkol goreng, pete goreng, pete bakar, pepes jamur, pete telor, pencok kacang, pencok leunca, ulukuteuk leunca, emping goreng. Dalam kategori sambal, menu yang unpopular adalah sambal tempe, sambal oncom, sambal tomat, sambal gandaria. Dalam kategori hidangan penutup, menu yang termasuk unpopular adalah biji salak, rujak serut, pisang goreng dan colenak.

Dalam kategori ikan menu yang klasifikasinya sangat popular yaitu menu gurame goreng, gurame baka dan gurame bakar cobek. Dalam kategori ayam menu yang klasifikasinya stars atau menu popular yaitu ayam goreng, ayam bakar dan ayam geprek goreng, menu yang klasifikasinya dog atau menu unpopular yaitu ati ampela goreng dan ati ampela bakar.

Di kategori hidangan laut tidak ada kategori menu yang unpopular tetapi terdapat menu yang klasifikasinya stars atau menu popular yaitu udang goreng mentega dan cumi goreng tepung. Dikategori nasi menunya semuanya termasuk menu yang popular.

Di kategori sayuran tidak ada menu yang klasifikasinya stars atau popular sedangkan yang kategorinya dog atau menu unpopular cukup banyak yaitu lotek, urab sayuran, tumis toge babat, lalab sambal, cobek genjer, pepes tahu, tahu goreng tepung, tempe goreng tepung, semur jengkol, jengkol goreng, pete goreng, pete bakar, pepes jamur, pete telor, pencok kacang, pencok leunca, ulukuteuk leunca dan emping goreng.

Dalam kategori sambal juga tidak terdapat menu yang kategorinya stars atau menu popular dan yang klasifikasinya dog atau menu unpopular yaitu sambal tempe, sambal oncom, sambal tomat dan sambal gandaria. Di kategori hidangan penutup 
semua menunya klasifikasinya dog atau menu unpopular yaitu biji salak, rujak serut, pisang goreng dan colenak.

Menu yang memiliki miller matrix yang bagus adalah karedok dan gurame goreng, sedangkan menu yang memiliki miller matrix yang rendah atau jelek adalah ikan mas goreng, ikan mas bakar.

Menu yang menguntungkan adalah sop ikan gurame dan gurame goreng dan menu yang tidak menguntungkan adalah pencok leunca dan ati ampela bakar.

Menu yang menguntungkan dalam cost margin analysis adalah sop ikan gurame dan menu yang tidak menguntungkan dalam cost margin analysis adalah pepes tahu.

Menu yang menguntungkan dalam food cost terhadap item number sold adalah ayam goreng, ayam bakar, sate ayam, karedok, sambal tempe terasi, empal goreng, tahu dan tempe goreng, sedangkan menu yang tidak menguntungkan dalam food cost terhadap item number sold adalah sop ikan mas.

Bahwa konsumen rata - rata tidak mengetahui menu tersebut baik secara pengetahuan maupun pernah mencoba hak ini dibuktikan dengan :

a) Hanya 33\% atau 10 menu dari 30 menu unpopular hasil penelitian terhadap konsumen yang diketahui oleh responden atau konsumen restoran dapur sunda.

b) Hanya 16,67\% atau 5 menu dari 30 menu unpopular yang pernah dikonsumsi oleh responden atau konsumen restoran dapur sunda.

Berdasarkan hal ini maka untuk menaikan atau memperbaiki menu unpopular yang ada di restoran dapur sunda salah satunya dengan cara

a) Melakukan promosi secara intensif terhadap menu - menu unpopular yang kurang diketahui oleh para konsumen restoran dapur sunda.

b) Mengganti atau menghilangkan menu - menu unpopular yang kurang diminati oleh para konsumen restoran dapur sunda.

c) Mempaketkan menu unpopular yang jarang dipesan oleh konsumen restoran dapur sunda dengan menu popular.

d) Membuat kartu menu unpopular yang dilengkapi dengan gambar agar para konsumen tertarik untuk membeli menu unpopular tersebut.

Berdasarkanpenelitianorganoleptik, maka jawaban panelis terbesar peneliti mendapatkan hasil sebagai berikut:

a) Dari segi rasa $33,98 \%$ yang memilih rasa dari menu unpopular biasa dan $27,29 \%$ yang memilih rasa dari menu unpopular enak, ini membuktikan bahwa tidak ada masalah dalam hal rasa.

b) Dari segi aroma 30,89\% yang memilih aroma dari menu unpopular biasa dan $27,30 \%$ yang memilih aroma dari menu unpopular menggugah selera, ini membuktikan bahwa tidak ada masalah dari hal aroma.

c) Dari segi penampilan $37,44 \%$ yang memilih penampilan dari menu unpopular biasa dan 22,43\% yang memilih penampilan dari menu unpopular menarik, ini membuktikan bahwa tidak ada masalah dari hal penampilan.

Sehingga dapat disimpulkan dari segi organoleptik bahwa tidak ada masalah dalam hal bahan baku menu tersebut, pengolahan makanan dari menu tersebut, platting dari menu tersebut sehingga kualitas produk yang ada di restoran dapur 
sunda secara keseluruhan memuaskan para konsumen restoran dapur sunda berdasarkan organoleptik menu.

Berdasarkan uji beda statistik (Least significant difference) pada taraf nyata $95 \%$ maka, analisis susunan menu perbulan pada penjualan berdasarkan volume penjualan, food cost, menu mix, dan contribution margin, menunjukkan tidak berbeda nyata atau sama. Hal ini menunjukkan bahwa secara penjualan sama tiap bulannya, tetapi berdasarkan hasil wawancara dengan konsumen, secara umum mereka menyatakan bahwa menu monoton secara perubahannya, sehingga konsumen tidak berpolemik tentang minat menu ketika waktu pemesanan menu. Hal ini bisa menjadi petunjuk baru dalam hal perbaikan menu unpopular dengan cara melakukan promosi, contohnya.

a. Melakukan perubahan menu secara statis misalnya bulan ke 1, melakukan promosi menu a, b, c dan bulan berikutnya menu yang lain secara bergantian. Hal ini dilakukan jika pengelola dan pemilik melakukkan pencitraan usaha melalui menu yang tetap.

b. Jika pengelola dan pemilik ingin melakukkan perubahan pencitraan usaha, maka perubahan menu dapat dilakukan secara dinamis berdasarkan hukum permintaan, citra usaha, volume penjualan, keuntungan perusahaan, event berkelanjutan dan lain lain.

c. Melakukan promosi berupa foto platting menu yg bergantian setiap waktu perperiodik, sehingga memunculkan kesan penampilan menu yang terus berbeda.

d. Untuk melakukan pemunculan baru diikuti dengan sosialisasi menu tiap bulan.

Dari hasil penelitian diperoleh bahwa tentang pengetahuan konsumen terhadap menu unpopular yang ada di restoran dapur sunda dan tentang karateristik organoleptik konsumen terhadap menu unpopular dapat diketahui bahwa :

a) Apabila menu tersebut klasifikasinya unpopular, kemudian konsumen tahu atau pernah mengkonsumsi dan dinyatakan tidak enak berdasarkan organoleptiknya (rasa, aroma dan penampilan) maka menu tersebut harus dihilangkan menu tersebut yaitu : pete bakar.

b) Apabila menu tersebut klasifikasinya unpopular tetapi konsumen tidak tahu ada menu tersebut atau konsumen tersebut belum pernah mengkonsumsinya maka harus dilakukan promosi yang lebih sering menu tersebut yaitu : pete telor, pencok kacang, pencok leunca dan colenak.

c) Apabila menu tersebut unpopular kemudian konsumen mengetahui menu tersebut tetapi tidak mengetahui tentang organoleptiknya (rasa, aroma dan penampilan) maka pihak restoran sebaiknya melakukan sampel atau di bagi gratis agar konsumen mengetahuinya menu tersebut yaitu : semur jengkol dan pepes jamur.

\section{KESIMPULAN}

Berdasarkan hasil penelitian dan analisis data yang telah dilakukan oleh penulis, maka kesimpulannya adalah sebagai berikut: 
1. Berdasarkan hasil analisis menu tiap bulanya ada yang mengalami perbedaan signifikan ada yang tidak mengalami perbedaan tidak signifikan ini berarti tiap bulan bulan tertentu ada menu yang harus di utamakaan dan ada menu yang harus digantikan terlebih dahulu.

2. Berdasarkan hasil penelitian menu unpopular dalam segi rasa tidak ada masalah dikarenakan kebanyakan konsumen menyukai rasa dari makanan tersebut dengan menu yang paling banyak disukai adalah jengkol goreng.

3. Berdasarkan hasil penelitian menu unpopular dalam segi aroma tidak ada masalah dikarenakan kebanyakan konsumen menyukai aroma dari makanan tersebut dengan menu yang paling banyak disukai adalah pisang goreng.

4. Berdasarkanhasil penelitian menu unpopular dalam segi penasmpilan tidak ada masalah dikarenakan kebanyakan konsumen menyukai penampilan dari makanan tersebut dengan menu yang paling banyak disukai adalah lalab sambal.

\section{DAFTAR PUSTAKA}

Baridwan Zaky (2004), Sistem Informasi Akuntansi, (Yogyakarta : Bagian Penerbitan Fakultas Ekonomi - Universitas Gajah Mada)

Bartono PH,SE. (2005), Analisis Food Product, (Yogyakarta : ANDI).

Bartanto dan Al Barry, Kamus Ilmiah Populer, (Surabaya: Arkola, 1994).

Eugen Pauli (1980), Classical Cooking The Modern Way, (London).

Gasperz (1994), Metode Perancangan Percobaan Untuk Ilmu - ilmu pertanian Teknik

Dan Biologi, (Bandung: Armiko).

Hubert E.Visick dan Peter Van Kleek (1974), MenuPlanning, (United State of America: McGraw-Hill,Inc).

Kardigantara Suseno (1990), Rekayasa menu, (STPB).

Kotas Richard dan Davis Bernard(1973)Food Cost Control.(Aylesbury, Bucks, England :Intertext Books)

Marom Chairul (2002), Sistem Akuntansi Perusahaan Dagang, (Jakarta : Grasindo)

Melliong, Metodologi Penelitian Kualitatif, (Bandung: Remaja Posda Karya, 2004),

Mulyadi (2005). Akuntansi Biaya,edisi ke-6. (Yogyakarta: STIE YKPN).

Nazir, M (2005). Metode Penelitian,(Bogor : Ghalia Indonesia).

Ninemeir.Jack.D. (1991) Planning and Control for Food and Beverage Management.

Sarah R. Labensky dan Alan M. Hause (1995), On Cooking, (New Jersey : PrenticeHall,Inc).

Simamora Henry (2002), Akuntansi Manajemen, (Jakarta: UPP AMP YKPN)

Subiyanto Ibnu, Metodologi Penelitian Manajemen dan Akuntansi, (Yogyakarta: UPP AMP YKPN, 2000).

Sudjana. (1996) metode statitik, (Bandung : Tarsito).

Soemarso (1983), Akuntansi Suatu Pengantar, (Jakarta : Lembaga Penerbit Fakultas

Ekonomi - Universitas Indonesia)

Soewarno TS (1985), Penilaian Organoleptik untuk industri pangan dan hasil pertanian, (Jakarta : Bhatara Karya Aksara).

Sugiyono.(2011). Statistika untuk penelitian.Bandung : CV Alfabeta. 
Paul R. Dittmer dan J.Desmond Keefe III (2006), Principles of Food Beverage and Labor Cost Control, (New Jersey : John Wiley \& Sons,Inc).

Wa, Marsun. (2005). Restoran dan Segala Permasalahannya. (Yogyakarta : Andy).

Wardiyanta (2010) Metode Penelitian Pariwisata, (yogyakarta : Andy).

Wilkie Susan (2008), get more Costumer Make More Money By The Menu Engginering Approach, (wilkie Enterprise And Corporation and The National Assosiation Of College And University Food Service).

Wiyasha I.B.M (2011), $F \&$ B Cost Control, (yogyakarta : Andy). 